\title{
Changes of catalytic mass grains morphology as a result of their surface covering with iron compounds
}

\author{
Maciej Dobrzański ${ }^{1, *}$, and Andrzej Jodłowski ${ }^{1}$ \\ ${ }^{1}$ Lodz University of Technology, Institute of Environmental Engineering and Building Installations, \\ 90-924 Lodz, Politechniki Ave 6, Poland
}

\begin{abstract}
There were operational problems of not having the ability to remove manganese compounds in one of the country's groundwater treatment plants, despite the fact that the filters were some years earlier fitted with the Multiman 3M catalytic bed inserts. The paper presents the results of analysis of morphological characteristics of fresh and blocked catalytic grains. An equivalent diameter, circularity, convexity, and compactness were used to describe the morphological characteristics of the catalytic mass grains. The obtained results confirmed the assumption that the grains of the catalytic mass were blocked by iron hydroxide and that the cause of WTP operating problems was the failure of the aerator, which resulted in the penetration of iron hydroxide through the upper sand bed layer into the lower catalytic mass layer.
\end{abstract}

\section{Introduction}

Groundwater is one of the main sources of tap water, especially in rural areas. The principal problem of groundwater treatment is usually the need of excessive concentrations of iron and manganese ions removal. Removal of $\mathrm{Fe}$ (II) and $\mathrm{Mn}$ (II) ions from water is usually achieved by oxidizing them to insoluble forms, which are then removed in the single- or two-stage filtration process through single or multi-layer beds. The iron removal process is relatively simple, usually involving the use of aeration, followed by filtration through a bed of quartz sand to retain the iron hydroxide precipitated from the water. It is much more difficult to remove manganese from water, whose oxidation requires alkalization of water to a $\mathrm{pH}$ of about 9.5 [1]. Adjustment of $\mathrm{pH}$ value is not necessary in the case of catalytic active masses. Oxidation of manganese in the catalyst bed is effective only after primary removing excess of iron from the water. Otherwise, the iron hydroxide can be precipitated and retained in the catalytic layer, which significantly reduces the manganese removal efficiency [2,3].

One of the WTP having maximum production of 37 $\mathrm{m}^{3} / \mathrm{h}$ use underground water and supplies treated water to rural distribution network. The water withdrawn from the deep well by the deep-well pump is pressed into the pressure aerator, from where through a set of three iron and manganese removing pressure filters it reaches the pressure booster system that provides the appropriate pressure in the distribution network. The filters are equipped with quartz sand beds of approx. $1.0 \mathrm{~m}$ height to ensure the retaining of precipitated iron hydroxide as a result of the aeration and at the bottom of the bed of the catalyst mass of Multiman 3M, approximately $0.4 \mathrm{~m}$ high. The Multiman $3 \mathrm{M}$ catalytic mass responsible for the removal of excessive manganese content is a filtration material whose main component is the $\mathrm{MnO}_{2}$ manganese ore $\left(\mathrm{MnO}_{2}\right.$ content of minimum $\left.82 \%\right)$.

After several years of operation, it was found that the concentration of manganese in treated water was more than three times the permissible value. Then the operator attempted to improve the efficiency of the water treatment by increasing the intensity and frequency of the filter backwashing. It was found that there was a failure of the aerator consisting in tearing the air dispersing grate. This was most probably due to the corrosion and dynamic loads of the aerator components. After the repair, further water quality tests were carried out, the results of which indicated an improvement in the removal of iron from water. The concentration of total iron reached the level below the limit value. The efficiency of manganese removal has not improved, however. The concentration of manganese level of treated water was maintained at $200 \mu \mathrm{g} \mathrm{Mn} / \mathrm{L}$, which was four times the acceptable value.

This paper presents the results of evaluation of the morphological characteristics of catalytic grains collected in a small rural WTP treating underground water, where the removal efficiency of manganese and iron was lost.

\section{Materials and methods}

\subsection{Materials}

The comparison of the morphological parameters of the fresh catalytic mass of Multiman 3M and the mass from the filters which did not provide the removal of

Corresponding author: maciej.dobrzanski@p.lodz.pl 
manganese from water, was made. According to the product data sheet specifications, the grains of the catalytic mass are characterized by irregular shape, rough surface and sharp edges. The granular mass of Multiman 3M in the form of brown and black granules is typically 1.0 to $3.0 \mathrm{~mm}$ or 0.8 to $2.5 \mathrm{~mm}$. The bulk density of the material is about $2.0 \mathrm{Mg} / \mathrm{m}^{3}$ at a specific density of $4.0-4.2 \mathrm{Mg} / \mathrm{m}^{3}$.

\subsection{Analytical methods}

Measurements and analysis of equivalent diameters and morphological parameters of catalytic mass grains were carried out using Malvern Morphologi G3 microscope image analyzer. As the morphological parameters were used equivalent diameter $\left(d_{e}, \mathrm{~mm}\right)$ - the diameter of the circle with the same surface as the image of the recorded particle, circularity - the ratio of the perimeter circle to the same surface as the particle divided by the perimeter of the actual particle image (assumes values from the nearest 0 to the value 1.0 for the ideal circle), solidity the actual surface of the particle divided by the surface of the tensile thread that enters the particle (assumes values from 0 to 1.0 - the ideal circle), elongation - takes values from 0 (ideal circle) to 1.0 , convexity - the ratio of the circumference of the tensile thread entangling the particle to the circumference of the actual particle (assumes values from 0 to 1.0 - perfectly smooth surface).

Additional research has also been carried out including bed porosity, bulk density and uniformity coefficient. Porosity of the bed was determined using the relationship (1).

$$
\varphi=\frac{V_{c}}{V}=\frac{Q-Q_{s}}{V \cdot \rho} \cdot 100 \quad[\%]
$$

in which $\varphi$ means porosity of the bed $(\%), \rho$ is specific density of the liquid phase in the bed $\left(\mathrm{g} / \mathrm{cm}^{3}\right), V$ is bed volume $\left(\mathrm{cm}^{3}\right), V_{c}$ refers to volume of liquid phase in the bed $\left(\mathrm{cm}^{3}\right), Q$ is mass of the bed $(\mathrm{g})$, and $Q_{s}$ is the mass of solid phase in the bed $(\mathrm{g})$.

Bulk density was determined according to the standard PN-EN 1097-3: 2000 [4].

The uniformity coefficient of grain size $(U)$ was calculated taking into account size of the grains together with the smaller ones accounted for $10 \%$ of the weight $\left(d_{10}, \mathrm{~mm}\right)$ and the size of grains, which together with the smaller ones account for $60 \%$ of the weight $\left(d_{60}, \mathrm{~mm}\right)$.

\section{Results and discussion}

\subsection{Results of morphological analysis}

The morphological analysis of fresh catalytic mass grains showed that the material used for the study was dominated by grains with an equivalent diameter $\left(d_{e}\right)$ of $1.0-3.0 \mathrm{~mm}$, which confirmed the information provided by the producer. The sample also had grains of lesser diameter equivalent $\left(d_{e}<1.0 \mathrm{~mm}\right)$, probably due to the fragmentation of the base material. They were, however, a small part of the volume of catalytic mass (about $3 \%$ ). Based on a statistical analysis of the distribution of values $d_{e}$, it was found that the equivalent of the grain is logarithmically normal (Fig. 1a).

In order to determine the distribution parameters, logarithm of the equivalent diameter values were calculated and it was found that the expected value of $d_{e}$ was of $1.67 \mathrm{~mm}$ with the standard deviation $\sigma=0.28$ $\mathrm{mm}$. Based on the results of the analysis of the catalytic mass extracted from the iron and manganese removal filter which was installed in the WTP where the loss of iron and manganese retention capacity has been observed, it was found that the equivalent diameter of the grains of the extracted material was mainly in the range $1.0-3.3 \mathrm{~mm}$ (Fig. 1b).
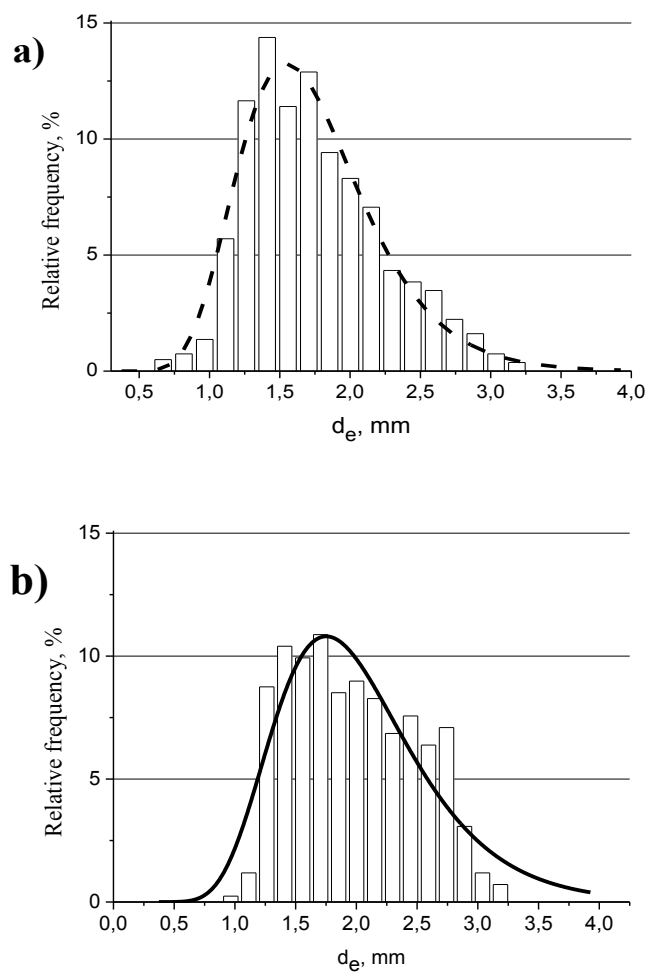

Fig. 1. Distribution of grains equivalent diameter $\left(d_{\mathrm{e}}\right)$ of (a) fresh and (b) blocked catalytic mass Multiman 3M.

No grains with a diameter of less than $1.0 \mathrm{~mm}$ have been found with such share as in raw material. Probably these small grains were removed from the filter bed as a result of its backwashing. As with the new material, the granulation of the spent bed material was subject to lognormal distribution. The expected $d_{e}$ value of $1.93 \mathrm{~mm}$ was determined and the standard deviation $\sigma$ was 0.42 $\mathrm{mm}$.

Comparing the results obtained for the blocked catalytic grains bed sample and for the fresh material, the expected value of the distribution of $d_{e}$ from $1.67 \mathrm{~mm}$ to $1.93 \mathrm{~mm}$ can be found with the increase in the size of large grains $\left(d_{e}>2.0 \mathrm{~mm}\right)$. This confirms the initial assumption that the coating of the catalytic grains with a thin layer of precipitated iron hydroxide should result in an increase in their equivalent diameter. 
Based on the cumulative mass distribution of the sample of fresh material, a diameter value of $d_{10}$ of 1.40 $\mathrm{mm}$ and $d_{60}$ of $2.22 \mathrm{~mm}$ were determined (Fig. 2). By specifying the grain size $U$ for a given sample 1.59 it can be stated that the material to be tested is coarse (equality for $1<U<5)$. In the case of blocked mass, the characteristic particle sizes $d_{10}$ and $d_{60}$ and were 1.60 $\mathrm{mm}$ and $2.48 \mathrm{~mm}$, respectively, and $U$-values of 1.55 , which also indicates the coarseness of the material being tested.

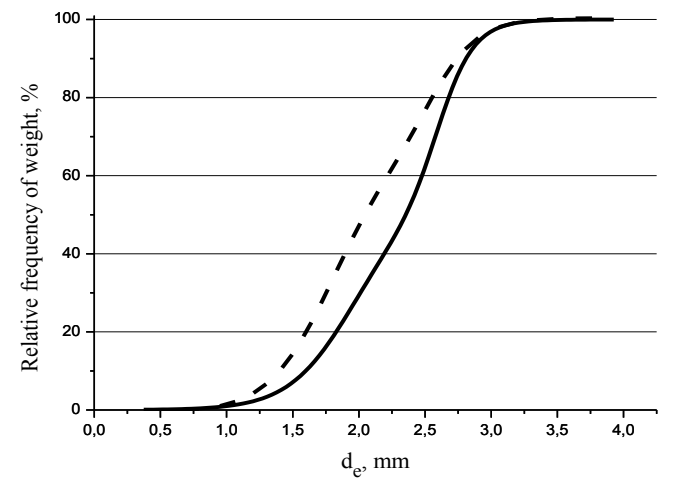

- - Fresh mass Multiman 3M — Blocked mass Multiman 3M

Fig. 2. Cumulative distribution of grains equivalent diameter $\left(d_{e}\right)$ of fresh and blocked catalytic mass Multiman 3M.

The greatest differences between the two samples under the comparison were found based on the results of the analysis of morphological parameters such as circularity, elongation, compactness, and convexity. On the basis of data obtained for both samples it was found, that morphological parameter distributions can mostly be presented using normal distribution. Coating the catalytic grains surface with a layer of iron hydroxide resulted in the shape of the grains being close to spherical. This is illustrated by a change in the expected value of the circularity parameter from 0.85 (fresh catalytic mass) to 0.93 (blocked mass) and the whole distribution of the circularity parameter for this sample shifts to 1.00 (Fig. 3a).

Comparing the values of the convexity parameter (Fig. 3b) determined for the mass of fresh and blocked catalytic mass, the value range was narrowed and the distribution was shifted toward the value of 1.00. In the case of the fresh catalytic mass, the value of the convexity parameter was between 0.91 and 0.97 and of the worn out mass were significantly narrower and ranged from 0.97 to 0.98 .

Significant change in morphological characteristics of fresh and blocked mass was noted in the parameter solidity (Fig. 3c). The value of this parameter fitted normal distribution and consisted mainly of between 0.91 and 0.97 in the case of the fresh catalytic mass. In the case of a blocked catalytic mass value of this parameter shifted to 1.00 . The sample consisted predominantly of grains having the value of solidity between 0.96 and 1.00 .

On the basis of differences in the values of the convexity and solidity parameters, it can be stated that the surface of catalytic grains covered with iron hydroxide had significantly reduced the active area. Grains covered with hydroxide layer had a much more smooth and regular surface. This negatively affects the ability to remove manganese from water.

a)
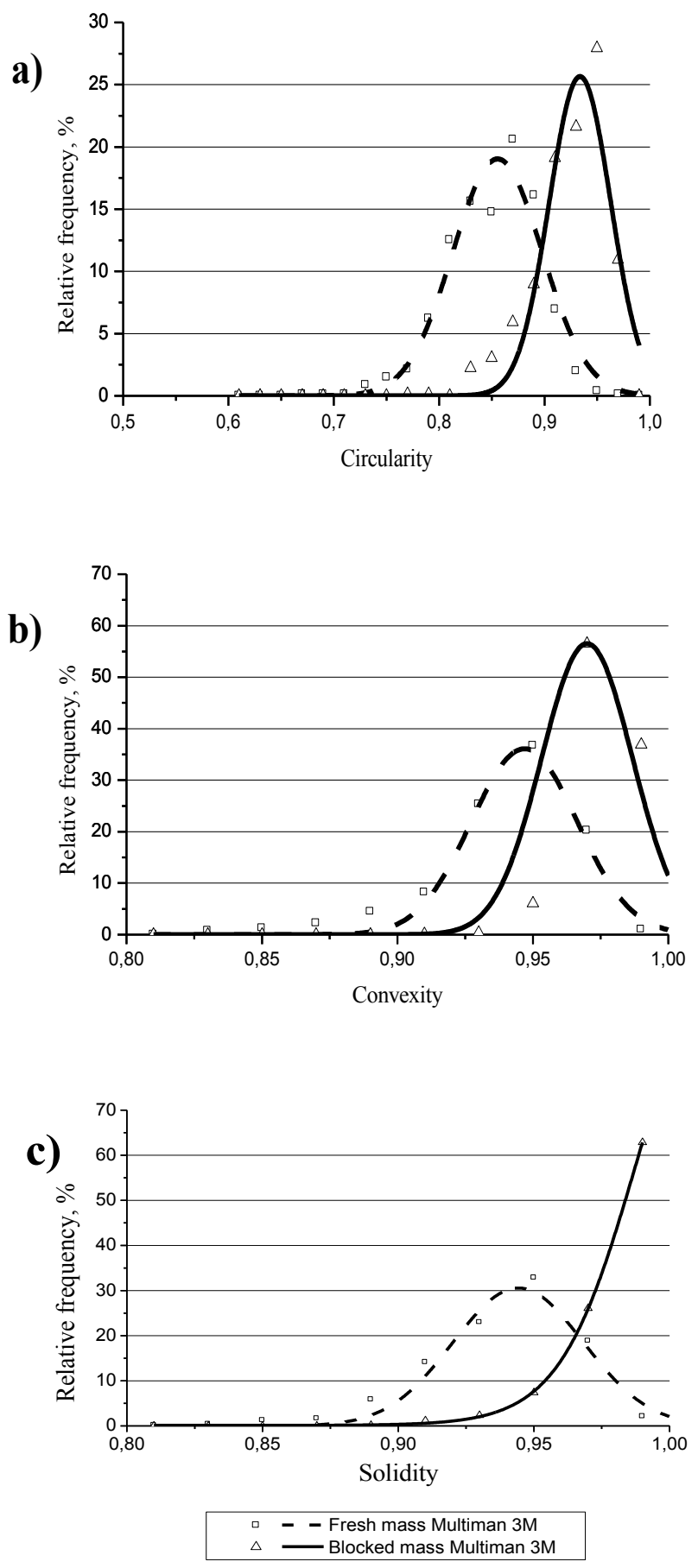

Fig. 3. Distribution of grains parameters circularity (a), convexity (b) and solidity (c) of fresh and blocked catalytic mass Multiman 3M.

List of the fresh $(F)$ and blocked $(B)$ Multiman $3 \mathrm{M}$ catalytic mass grains morphological parameters is presented in Table 1.

Photographs taken with the use of the image analyzer enabled the assessment of the grain surface covered by the layer of accumulated iron hydroxide (Fig. 4). 
Table 1. Listing of the fresh $(F)$ and blocked $(B)$ Multiman 3M catalytic mass grains morphological parameters.

\begin{tabular}{|c|c|c|c|c|c|}
\hline \multicolumn{2}{|c|}{$\begin{array}{c}\text { Distribution } \\
\text { parameter }\end{array}$} & \multirow{2}{*}{$\begin{array}{c}\text { Expected } \\
\text { value }\end{array}$} & $\begin{array}{c}\text { Standard } \\
\text { deviation, } \\
\boldsymbol{\sigma}\end{array}$ & \multicolumn{2}{c|}{ Percentile } \\
\cline { 4 - 6 } $\begin{array}{c}\text { Equivalent } \\
\text { diameter, } \\
d_{e}, \mathrm{~mm}\end{array}$ & $F$ & 1.67 & 0.28 & 2.44 & 1.23 \\
\cline { 2 - 6 } Circularity & $B$ & 1.93 & 0.42 & 2.71 & 1.33 \\
\cline { 2 - 6 } & $F$ & 0.85 & 0.04 & 0.90 & 0.80 \\
\hline \multirow{2}{*}{ Convexity } & $F$ & 0.94 & 0.02 & 0.97 & 0.91 \\
\cline { 2 - 6 } & $B$ & 0.98 & 0.02 & 0.98 & 0.97 \\
\hline \multirow{2}{*}{ Solidity } & $F$ & 0.94 & 0.02 & 0.97 & 0.90 \\
\cline { 2 - 6 } & $B$ & $0.98 *$ & 0.02 & 1.00 & 0.96 \\
\hline \multirow{2}{*}{ Elongation } & $F$ & 0.25 & 0.13 & 0.43 & 0.09 \\
\cline { 2 - 6 } & $B$ & 0.20 & 0.12 & 0.37 & 0.08 \\
\hline
\end{tabular}

* without fitting the distribution
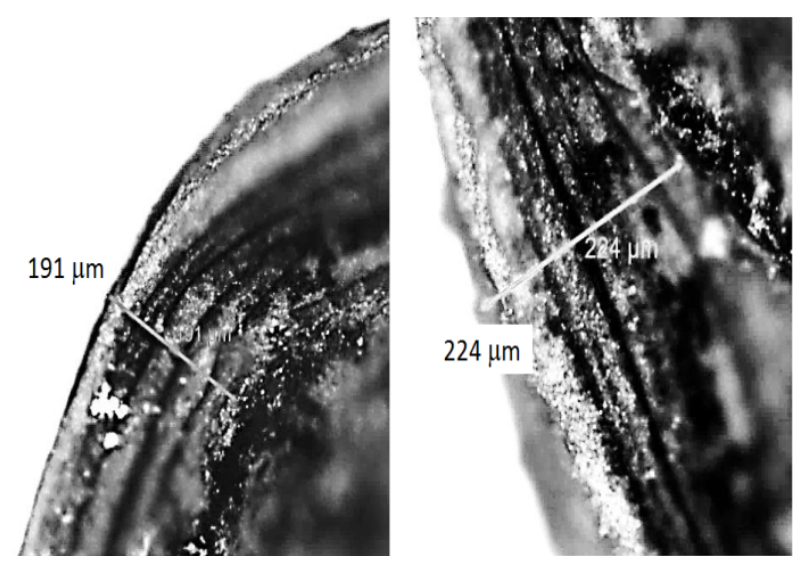

Fig. 4. Pictures of the surface of the blocked catalytic mass with the blocking layer of iron hydroxide.

The deposit cross section shows that it consists of several layers alternately arranged in light and dark material. This can be attributed to the long-term deposition process.

It can be assumed that the light-colored layer is iron hydroxide separated by layers of dark material. Probably it is a dust of catalytic mass from the abrasive grains, which was formed during the intense backwashing that was as attempt of trying to improve the situation.

\subsection{Changes in the filtration bed bulk density and porosity as a consequence of the ferric hydroxide layer deposition}

Changes in the diameter and morphological parameters of the catalytic mass have resulted in a change in the bulk density. For the fresh catalytic mass it was of 1.72 $\mathrm{Mg} / \mathrm{m}^{3}$. According to the manufacturer the bulk density is about $2.00 \mathrm{Mg} / \mathrm{m}^{3}$. The mass blocked with iron hydroxide decreased to the value of $1.42 \mathrm{Mg} / \mathrm{m}^{3}$. Increasing the compactness and circularity of grains and their diameter probably resulted in larger spaces between the grains and thus resulted in a lower bulk density. In order to verify the validity of this thesis the porosity of both masses was measured. In the case of a fresh mass. the porosity amounted to $38 \%$. while in the case of used mass amounted to $49 \%$. The increase in porosity of the bed proves that the proportion of free space in the total volume of the bed increased in the mass blocked with iron hydroxide in comparison with fresh mass.

The close relationship between the porosity of the bed with the size of its grains has been demonstrated by Nowak [5]. who stated that as the active mass grains diameter increases. the porosity of the bed increases. For example. the smallest porosity $(41 \%)$ was determined for Purolite MZ-10 with a grain size of less than $1 \mathrm{~mm}$. while the largest (52\%) for the Defeman catalytic mass. which $90 \%$ of grains had a diameter greater than 1.6 $\mathrm{mm}$.

\section{Conclusions}

The coating of the catalytic grains with the precipitated iron hydroxide eventually led to an increase in their diameter. a decrease in porosity and an active surface. The thickness of deposit layer accumulated on the surface of the catalytic mass grains was estimated at 102 to $284 \mu \mathrm{m}$. Over time, the ability to remove manganese from water has been almost completely lost. The greater porosity and diameter of the bed grains of the blocked catalytic mass has probably resulted in smaller flow resistances. Those in turn meant higher filtration velocity. which ultimately led to "break through" the bed and worsened the efficiency of iron removal.

\section{References}

1. M.K. Doula, Wat. Res. 40, 17 (2006)

2. T. Siwiec. Przegl. Nauk. Inż. Kształt. Środ. 53, (2011)

3. M. Kalenik. D. Morawski, Polska Akademia Nauk. IV, 3 (2013)

4. PN-EN 1097-3:2000 Tests of mechanical and physical properties of aggregates - Determination of bulk density and cavity.

5. R. Nowak. J. Ecol. Eng. 17, 5 (2016) 